\title{
Is there a suburban sleeping sickness in Libreville?
}

\author{
*Kohagne Tongué L ${ }^{1}$, Mavoungou JF², Fako Hendji GC³ , Pamba R ${ }^{4}$, Mbatchi B ${ }^{2}$
}

1. University of Yaoundé 1, Yaoundé, Cameroon

2. Université des Sciences et des Techniques des Sciences de Masuku, Franceville, Gabon

3. Université Catholique d'Afrique Centrale, Yaoundé, Cameroun

4. Institut d'Hygiène Publique et d'Assainissement, Libreville, Gabon

\begin{abstract}
Background: The transmission of sleeping sickness occurs primarily in rural areas, and exposed populations are those living from rural activities such as agriculture, fishing, animal husbandry or hunting. However, urban and suburban foci are more and more reported in T. b. gambiense areas. In Libreville town, sleeping sickness cases are regularly diagnosed. In order to investigate about the establishment of a transmission cycle of that disease, we have carried out an entomological survey in two quarters in the vicinity of the town.

Methods: Vavoua traps were set out in all suitable biotopes for tsetse flies during four days and examined twice a day. Flies were collected, identified and dissected.

Results: Two species of Glossina were caught: G. palpalispalpalis $(90.58 \%)$ and G. caliginea (9.42\%). A total infection rate of $9.37 \%$ was observed after dissection of all non-teneral flies captured.

Conclusion: These results suggest the establishment of a trypanosomiasis transmission cycle in the area. No salivary gland was found infected. Given that infected persons are regularly detected, we can think about the existence of a suburban sleeping sickness focus in Libreville. More analysis is needed concerning the identification of human trypanosomes and the origin of Glossina blood meals that may confirm the existence of that focus.
\end{abstract}

Key words: sleeping sickness, suburban focus, Glossina, Libreville, Gabon.

African Health Sciences 2013; 13(2): 266 - 269 http:/ / dx.doi.org/10.4314/ahs.v13i2.10

\section{Introduction}

Sleeping sickness also known as Human African trypanosomiasis (HAT) is a vector-borne disease restricted to sub-Saharan Africa, in the range of the tsetse vector or Glossina Wiedemann, 1830. The chronic form due to Trypanosoma brucei gambiense Dutton, 1902 occurs in Central and Western Africa and it accounts for 97 percent of reported cases. The acute infection (from a few weeks to a few months) is caused by Trypanosoma brucei rhodesiense Stephens \& Fantham, 1910 and is found in Southern and Eastern Africa.

The distribution of tsetse flies (more than 30 species with affinities for specific habitat) and of the parasites within the vector range, are both focal. Thus, HAT is a public health problem where the vector, the parasite (and its reservoir hosts), and humans co-exist ${ }^{1}$.

\footnotetext{
*Corresponding author:

Kohagne L. Tongué

University of Yaoundé 1. BP 2816,

Yaoundé-Ngousso, Cameroon

Tel.: 0023722103849

Email: lisetteappmv@yahoo.fr
}

The transmission of HAT occurs primarily in rural areas, and exposed populations are those living from rural activities such as agriculture, fishing, animal husbandry or hunting. However, urban and suburban foci are more and more reported in T. b. gambiense $\operatorname{areas}^{2,3}$. The frequent detection of sleeping sickness cases in an area not absolutely suggests that the area may be a HAT focus, since there are some rural foci with urban manifestation ${ }^{3}$. A local transmission of HAT is confirmed when a local contact between tsetse flies and human is demonstrated (origin of tsetse blood meal) and the human trypanosome ( $T$. b. gambiense) identified. We are presented results about an entomological survey which suggest the existence of a suburban sleeping sickness focus in Libreville.

\section{Methods \\ Study area}

Libreville $\left(0^{\circ} 23^{\prime} 24^{\prime \prime} \mathrm{N}\right.$; 9 $\left.9^{\circ} 27^{\prime} 15^{\prime \prime} \mathrm{E}\right)$ is the capital city of Gabon. It conveniently runs along the shores of South Atlantic Ocean (figure 1) and features a tropical monsoon climate with a lengthy wet season and a short dry season. Being situated near the ocean, the beaches are popular for locals and tourists. There is 
a large port on the north bank of the estuary which collects water from and their tributaries. The continuous growing of populations (annual growth rate: $2.7 \%$, EDSG report, unpublished) has extended the city nearby the flooded area and swamp mangrove around the Estuary. between thumb and index fingers and by the residual sac from the larval stage in the midgut.

\section{Data analysis}

Apparent density per trap and per day was calculated as follows:

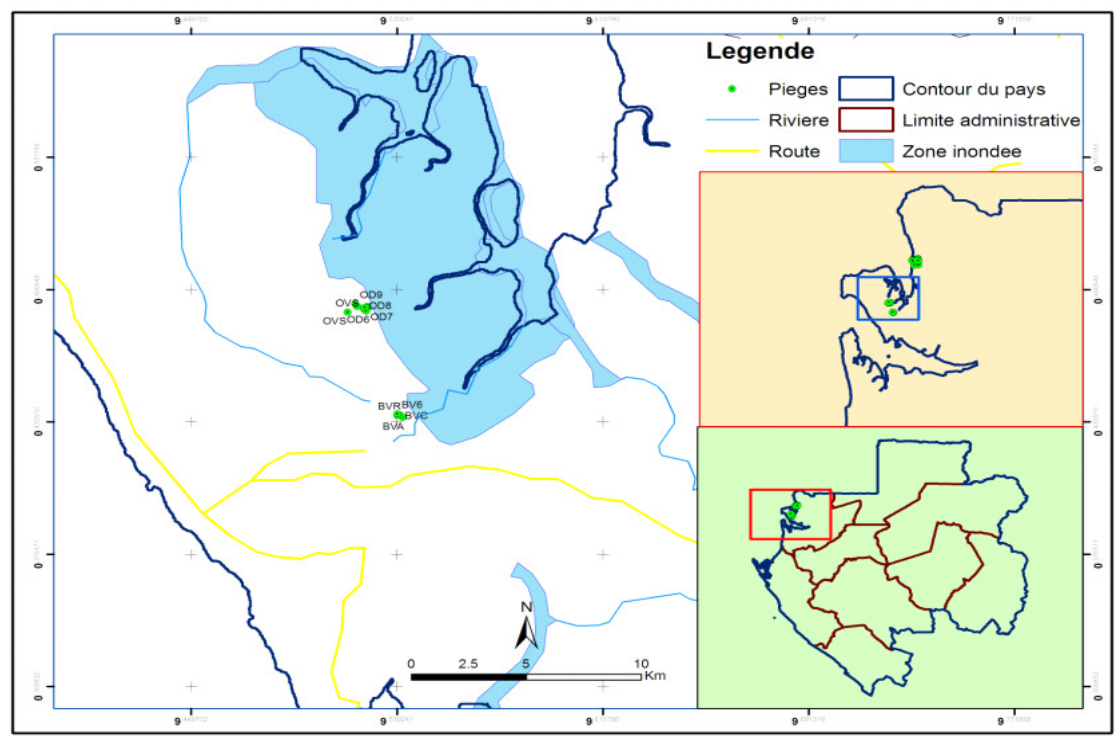

Figure 1:The trapping sites in the survey area

\section{Entomological survey}

The survey was conducted in two quarters located in the $6^{\text {th }}$ administrative district: Bambouchine and Oveng where 3 HAT cases were passively diagnosed in 2010 (annual report of the National HAT control program, unpublished). Those sleeping sickness cases were fishermen and it was not possible to define with precision their contamination site since they are going over the tsetse infected coastal area of the country during the course of their activity.

Vavoua traps ${ }^{4}$ were set out in all suitable biotopes for tsetse flies: landing stages, water spots, orchards, damp valleys, footpaths and at the border of huts. Each trap site was cleared to ensure reasonable visibility of the trap and traps were examined twice a day, at 10 a.m. and at 4 p.m., during four days. Data on the species and sex of tsetse captured in each trap were recorded according to the computer based identification key for tsetse flies ${ }^{5}$. Flies were dissected $24 \mathrm{~h}$ after capture in a drop of sterile $0.9 \%$ saline water on a microscope slide under a magnifying glass. Midgut, proboscis and salivary glands were examined under a light microscope at a 400X magnification, for the search of trypanosomes. Teneral flies were identified by the light compression

\section{$A D T=\frac{\text { Number of Glos } \sin \text { a captured }}{\text { Number of traps } x \text { Number of days }}$}

Infection rate was expressed as the percentage of the number of infected flies divided by the total number of dissected flies and the index of trypanosomosis risk was obtained by multiplying the ADT and the infection rate. The nonparametric Mann-Whitney test was performed to compare data after discrimination made by Kruskall-Wallis test.

\section{Results}

A total of 138 Glossina were captured in all biotopes screened, except along footpaths. Two species and sub-species of Glossina were captured: Glossina palpalis palpalis Robineau-Desvoidy, 1830 (125; 90.58\%) and Glossina caliginea Austen, 1929 (13; 9.42\%). Apparent density per trap (ADT) was not significantly different per biotopes $(\mathrm{p}>0.05)$ but the highest ADT was observed in landing stages (table 1). G. palpalispalpalis was found in all biotopes while $G$. caliginea were found only in landing stages. Teneral flies of $G$. palpalis palpalis were captured in water spots and in damp valleys. Females were more captured (sex ratio $=0.61)$ and more infected than males. The total infection rate was $9.37 \%$ after dissection of all nonteneral flies. Midgut was the only infected organ and 
all infected flies were caught in landing stages. Then, trypanosomosis risk was observed only in landing stages.

Table 1: Entomological field data

\begin{tabular}{llll}
\hline Site/biotope & $\begin{array}{l}\text { ADT } \\
(\mathrm{g} / \mathrm{t} / \mathrm{d})\end{array}$ & $\begin{array}{l}\text { Infection } \\
\text { rate } \%)\end{array}$ & $\begin{array}{l}\text { Index of } \\
\text { trypanos- } \\
\text { omosis } \\
\text { risk }\end{array}$ \\
\hline Landing stages & 6.5 & 13.33 & 0.73 \\
Border of huts & 0.22 & 0 & 0 \\
Damp valleys & 0.5 & 0 & 0 \\
Orchards & 4.83 & 0 & 0 \\
Water spots & 3.66 & 0 & 0 \\
Foot paths & 0 & 0 & 0 \\
\hline
\end{tabular}

\section{Discussion}

This study confirmed the presence of tsetse flies in the coastal area of Gabon. Glossina was caught in almost all biotopes screened (a part of footpaths), because of suitable environmental conditions (temperature, moisture, luminosity) for their survival that prevails in the area. Fly densities are determined by the availability of hosts and suitable habitats ${ }^{6}$. That area is almost uninhabited. In the past, it was used only by fishers for anchorage; thus, many landing stages are built there in swamp mangrove. We did not analyze Glossina blood meals but it seems obvious that wild animals, abundant in the area ${ }^{7}$ have favored tsetse infestation. Two species of Glossina were captured: Glossina palpalis palpalis and Glossina caliginea. These results agree with observations made by previous authors ${ }^{7}$ who showed the predominance of G. palpalis palpalis in the Estuary of Gabon. The presence of $G$. caliginea would be due to their alliance with mangrove forest. Teneral flies were observed only in water spots and damp valleys. This suggests that these biotopes may be reproduction sites of Glossina in that area. Indeed, Glossina larva need moisturized sites for its development. The structure, compaction, temperature and moisture of the ground of all that survey area is suitable for Glossina larvae development, but, in swamp mangrove where are built landing stages, there is a frequent variation of tide that impede the maturation of larvae. Nevertheless, it was in that biotope that where observed infected flies. Knowing that a tsetse fly must be teneral to become infected ${ }^{8}$, we can argue that presence of infected flies in landing stages is a consequence of flies' dispersion, essentially devoted to searching for food, favorable resting places, laying places for females and young females for males.

Identification of infected tsetse flies confirmed the existence of a local transmission cycle in the area. No salivary gland was found infected and we did not carry out further analysis for determining the species of trypanosomes. Then, we can't state about the evidence of a human transmission cycle. But, as passive sleeping sickness cases are currently detected in the area, we should state that the suburban area of Libreville is at risk of trypanosomiasis. In previous studies, it was assumed that the regular frequentation of fishers (most infected group-workers) in tsetse infested areas for their activities, would contribute to the dissemination of the parasite in the coastal area of Gabon ${ }^{9}$.

The probable endemicity of sleeping sickness in the suburban area of Libreville is a serious problem in term of public health. Nowadays, the area is ill-frequented, either for trade (fishermen, fishmongers ...), or for tourism. Thus, everyone, regularly present in the area may be exposed to the disease. HAT transmission depends not only on the sites, but also on the intensity and frequency of contact between Glossina and humans. The consequence of this general exposure is that even Europeans living in Libreville may become infected ${ }^{10}$ . As clinical signs of sleeping sickness are generally unspecific and exposed populations are scattered in Libreville downtown, it will be difficult to control that disease by case-control strategy. Besides, infected people, particularly those in the early stage of the disease (which may last for several years) are an important reservoir since they can continue their normal activities while the parasite circulates in their blood and remains available to the vector. Libreville is the main populated town of Gabon. The presence of a suburban sleeping sickness focus in that area may seriously impede the development of that country. We suggest that vector control activity be integrated into the national sleeping sickness control program.

\section{Acknowledgments}

Authors are grateful to the personal of the "Institut d'Hygiène Publique et d'Assainissement" of Gabon for their technical assistance. 


\section{References}

1. Cattand P, Jannin J, Lucas P. Sleeping sickness surveillance: an essential step towards elimination. Trop Med Int Health 2001; 6 (5): 348-361.

2. Louis FJ, Mia bilengue CM, Lucas P, Jannin J : La trypanosomose humaine africaine en milieu urbain: une problématique émergente. Gème Congrès International Francophone, 2001.

3. Courtin F, Dupont S, Zeze DG, Jamonneau V, Sané B, Coulibaly B, Cuny G, Solano P : Trypanosomose Humaine Africaine: transmission urbaine dans le foyer de Bonon (Côte d'Ivoire). Trop Med Int Health 2005; 10 (4): 340-346.

4. Laveissière C, Grébaut P. Recherches sur les pièges à glossines (Diptera; Glossinidae). Mise au point d.un modèle économique: le piège «Vavoua». Ann Trop Med Parasitol 1990; 41: 185192.

5. Brunhes J, Cuisance D, Geoffroy B, Hervy JP. Les glossines ou mouches tsé-tsé. Logiciel d'identification et d'enseignement. Editions ORSTOM, Montpellier, France, 1998.

6. Leak SGA. Tsetse biology and ecology. Their role in the epidemiology and control of trypanosomiasis. CABI Publishing, New York, USA, 1999.
7. Challier A. Enquête sur les glossines des foyers de trypanosomiase humaine en République du Gabon - Prospection des gites de l'Estuaire et de l'Ogooué Maritime. Recommandations pour une campagne de lutte. Rapport final Organisation mondiale de la santé, Bureau Régional de l'Afrique, 1970.

8. Dukes HL. Studies on the factors that may influence the transmission of the polymorphic trypanosomes by tsetse. IX. On the infectivity to Glossina of the trypanosome in the blood of mammal. Ann Trop Med Parasitol 1935; 29: 131143.

9. Kohagne Tongué L, Gounoue Kamkumo R, Kaba D, Mengue M'Eyi P, Mimpfoundi R, Louis FJ. Enquête entomologique dans le foyer historique de trypanosomiase humaine africaine de la Bendjé (Gabon) Parasite 2011 ; 4(18): 303309.

10. Gautret P, Clerinx J, Caumes E, Simon F, Jensenius M, Loutan L, P Schlagenhauf, F Castelli, D Freedman, A Miller, U Bronner, P Parola. Imported human African trypanosomiasis in Europe, 2005-2009. Euro Surveillance 2009; 14(36): [http: / / www.eurosurveillance.org / ViewArticle.aspx?ArticleId=19327]. 